\title{
Investigation of a Mechanism for Accelerated Breakdown of Immune Tolerance to the Primary Biliary Cirrhosis-Associated Autoantigen, Pyruvate Dehydrogenase Complex
}

\author{
David E. J. Jones, Jeremy M. Palmer, Kate Bennett, Amanda J. Robe, \\ Stephen J. Yeaman, Helen Robertson, Margaret F. Bassendine, Alastair D. Burt, \\ and John A. Kirby
}

Centre for Liver Research, University of Newcastle, Framlington Place, Newcastle-upon-Tyne, United Kingdom

SUMMARY: Primary biliary cirrhosis (PBC) is an autoimmune liver disease characterized by autoreactive T- and B-cell responses to the highly conserved enzyme pyruvate dehydrogenase complex (PDC). In this study we have examined the breakdown of T-cell tolerance to self-PDC using a mouse model. Female SJL/J mice were sensitized intraperitoneally with foreign-PDC (bovine) and/or self-PDC (murine) in complete Freund's adjuvant, and serum, spleen, and liver tissue was taken 8 weeks later. Animals sensitized with foreign-PDC produced IgG antibodies that were reactive with both foreign and self-PDC, but splenic T cells from these animals only responded to stimulation with foreign PDC. Sensitization with self-PDC elicited neither antibodies nor reactive T cells. Significantly, cosensitization with mixed self-PDC and foreign-PDC resulted in a full breakdown of self-tolerance, with generation of both antibody and T-cell responses to self-PDC of the type seen exclusively in human PBC patients. Mild bile duct lesions deficient in $\mathrm{CD}^{+}{ }^{+}$T cells were seen 8 weeks after sensitization with either foreign or self-PDC. However, after sensitization with mixed self-PDC and foreign-PDC, these lesions were significantly larger and heavily infiltrated by $\mathrm{CD}^{+} \mathrm{T}$ cells. Liver-infiltrating T cells derived from the self-PDC and foreign-PDC cosensitized but not from control animals showed reactivity with self-PDC, suggesting a possible role for autoreactive PDC-specific T-cell responses in the pathogenesis of the observed histologic changes. It is likely that B-cell cross-reactivity between foreign and self-PDC enhances the potential for breakdown of T-cell self-tolerance by allowing efficient presentation of self-antigens in the inoculum. This model may provide a useful system for investigating the etiology and treatment of PBC. (Lab Invest 2002, 82:211-219).

$B$ reakdown of immune tolerance to the highly conserved mitochondrial self-antigen pyruvate dehydrogenase complex (PDC) is the characteristic immunologic motif of the autoimmune cholestatic liver disease primary biliary cirrhosis (PBC) (Yeaman et al, 2000). In excess of $95 \%$ of patients with PBC have serum antibodies reactive with the inner lipoyl domain of the dihydrolipoamide acetyltransferase (E2) and the E3 binding protein (E3BP) components of self-PDC (Dubel et al, 1999; Palmer et al, 1993, 1999; Surh et al, 1990). Moreover, peripheral blood T cells reactive with self-PDC-E2 are present in the majority of patients with PBC but absent from normal controls (Jones et al, 1997; Shimoda et al, 1995). Elucidation of the mechanism leading to breakdown of self-tolerance to PDC is therefore critical for our understanding of the pathogenesis of PBC. Murine modeling studies have recently provided an experimental setting in which to

Received November 27, 2001.

This work was supported by the Medical Research Council.

Address reprint requests to: Dr. D. E. J. Jones, Centre for Liver Research, 4th Floor, William Leech Building, The Medical School, Framlington Place, Newcastle-upon-Tyne, NE2 4HH, UK. E-mail: D.E.J.Jones@ncl.ac.uk prospectively study mechanisms of breakdown of tolerance to self-PDC of potential relevance for our understanding of the pathogenesis of PBC (Jones et al, 1999, 2000)

Despite the apparent importance of the breakdown of immune tolerance to self-PDC in the pathogenesis of PBC, it is unclear how this failure of immune regulation occurs. Given the presence of highly conserved PDC in all organisms from primitive prokaryotes upwards, it is possible that induction of an immune response to non-self-PDC, in the context of infection by PDC-containing organisms, simply results in a cross-reactive response to self-PDC. There is some evidence to support this hypothesis (Haydon and Neuberger, 2000), including an apparently increased prevalence of active bacterial infection (Burroughs et al, 1984; Butler et al, 1993) and serologic markers of previous infection in patients with $\mathrm{PBC}$ (Mayo et al, 2000). Evidence against this simple molecular mimicry model comes, however, from other clinical studies that have failed to demonstrate increased prevalence of bacterial infection in patients with PBC (Floreani et al, 1989; Howel et al, 2000) and the difficulty in envisaging how an event that occurs in all individuals at some point in their life (bacterial 
infection) can give rise to a rare pathologic process (PBC).

Observations made in human disease states, and more recently in animal modeling studies, have suggested a more complex relationship between immunologic exposure to foreign-PDC and the subsequent breakdown of tolerance to self-PDC. Patients with acute mycobacterial infection (Klein et al, 1993) and recurrent urinary tract infection (Butler et al, 1995) have been demonstrated to have serum antibodies reactive with self-PDC in the apparent absence of other immunologic or pathologic features of PBC. In mice, the majority of strains show, after immunization with non-self-PDC, a similar pattern of induction of anti-self-PDC antibody responses in the absence of any apparent pathology (Jones et al, 2000; Krams et al, 1989). These observations suggest that the breakdown of tolerance to self-PDC is a split phenomenon with a critical controlling step at the point of extension from breakdown of B-cell tolerance (an apparently common event of seemingly limited pathologic significance) to T-cell tolerance breakdown and the development of overt disease (a much more restricted phenomenon).

We have recently demonstrated that SJL/J mice, in contrast to other strains, show a slow breakdown of T-cell tolerance to self-PDC over 30 weeks after sensitization with foreign-PDC (Jones et al, 1999). In demonstrating the full breakdown of tolerance to self-PDC characteristic of human PBC, the PDCsensitized SJL/J mouse represents a potentially useful model in which to study pathways of full tolerance breakdown of PDC of relevance for our understanding of the pathogenesis of PBC. In this study we set out to further explore the phenomenon of breakdown of T-cell self-tolerance to PDC in the SJL/J mouse model.

\section{Results}

\section{Anti-PDC Responses in Self-PDC Sensitized Mice}

Initially we assessed the natural state of tolerance to self-PDC of SJL/J mice by challenging them with self-PDC (mouse PDC) alone. No antibody reactivity was seen against either self-PDC or foreign (bovine) PDC in mice $(n=8)$ at 8 weeks after challenge with self-PDC alone (Fig. 1). Furthermore, splenic T cells from self-PDC-challenged animals showed no proliferative response (Fig. 2a) or IFN- $\gamma$ production (Fig. 2b) after in vitro stimulation with either self-PDC or foreign-PDC. Hence, injection of mouse PDC in complete Freund's adjuvant (CFA) was unable to break normal immune tolerance of self-PDC in SJL/J mice. This normal state of full tolerance to self-PDC mimics that seen in non-PBC controls in previous human studies of B-cell and T-cell reactivity to self-PDC (Jones et al, 1997; Palmer et al, 1993)

\section{Anti-PDC Responses in Foreign-PDC Sensitized Mice}

As has previously been demonstrated (Jones et al, 1999), mice sensitized with foreign-PDC $(n=8)$ de-

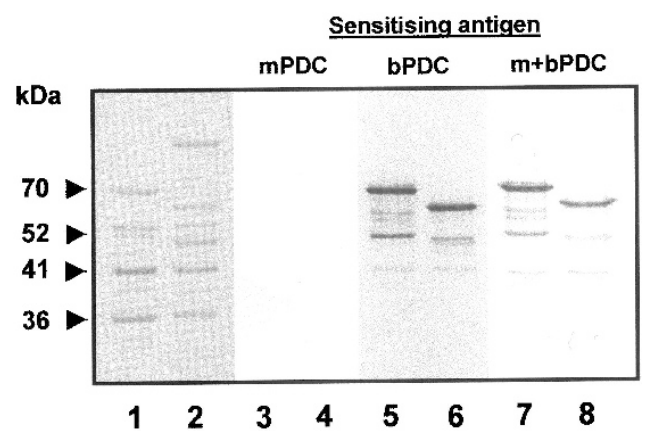

Figure 1.

Immunoblot of serum from representative self-pyruvate dehydrogenase complex (PDC)-sensitized (lanes 3 and 4), foreign PDC-sensitized (lanes 5 and 6), and self-PDC and foreign PDC cosensitized (lanes 7 and 8) mice blotted against self-PDC (mouse) (lanes 3, 5, and 7 ) and foreign PDC (bovine) (lanes 4, 6, and 8). Representative protein staining of bovine PDC (lane 1) and the mouse PDC/OGDC preparation (lane 2) is also shown.

veloped high-titer serum antibody responses against that foreign PDC. These antibodies were crossreactive with self-PDC (Fig. 1). Significant in vitro T-cell proliferative responses (Fig. 3a) and the induction of IFN- $\gamma$ production (Fig. 3b) were seen after stimulation of splenic cells from these animals with foreign-PDC. However, at the 8-week time point after sensitization adopted in this study, no T-cell response was observed after in vitro stimulation with self-PDC (Fig. 3, a and b). Therefore, sensitization with foreignPDC elicited a T-cell response specific exclusively for nonconserved epitopes on the foreign protein, but the IgG response helped by these T cells was fully crossreactive between both foreign and self-PDC.

\section{Anti-PDC Responses in Mice Cosensitized with both Foreign and Self-PDC}

In contrast to mice sensitized with either foreign or self-PDC alone, splenic cells from animals sensitized with mixed foreign and self-PDC $(n=8)$ showed a significant in vitro T-cell proliferative response (Fig. 4a) and the induction of IFN- $\gamma$ production (Fig. 4b) after in vitro challenge with self-PDC. Hence, simultaneous immunologic coexposure to self-PDC and foreignPDC gives rise to an early and aggressive full breakdown of T-cell and B-cell tolerance of self-PDC. This breakdown of tolerance mimics that seen in human PBC.

\section{Pathologic Features in Foreign-PDC, Self-PDC, and Cosensitized Mice}

Light microscopy of hematoxylin and eosin (HE)stained liver sections from the self-PDC and foreignPDC cosensitized animals showed a predominantly lymphocytic infiltrate that was centered on the portal tracts and sometimes completely obscured the bile ducts (representative lesion, Fig. 5a). HE sections from animals sensitized with self-PDC showed variability between animals. However, the portal tract inflammatory changes were less marked than those in cosensitized animals and were similar in extent to those 
a)

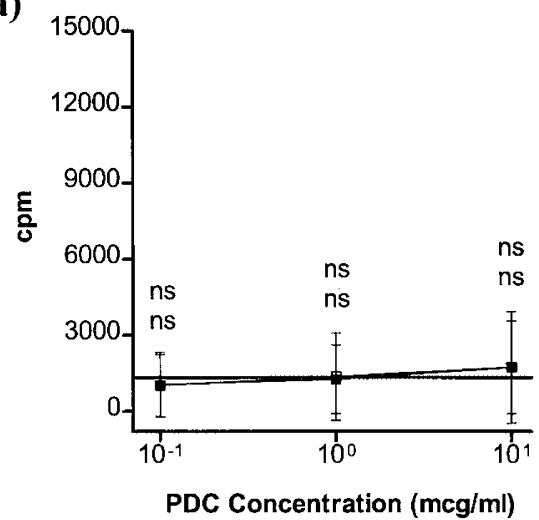

b)

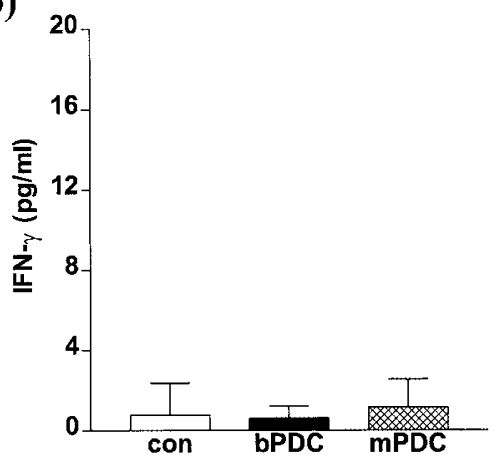

Figure 2.

T-cell proliferative (a) and IFN- $\gamma$ secretory (b) responses of mice sensitized with self-PDC to foreign PDC (solid squares) and self-PDC (open squares) at a range of protein concentrations. The horizontal line indicates mean control proliferation; each point represents the mean of data from eight animals, and the error bar shows the standard deviation. $\mathrm{ns}=$ not significant.

a)

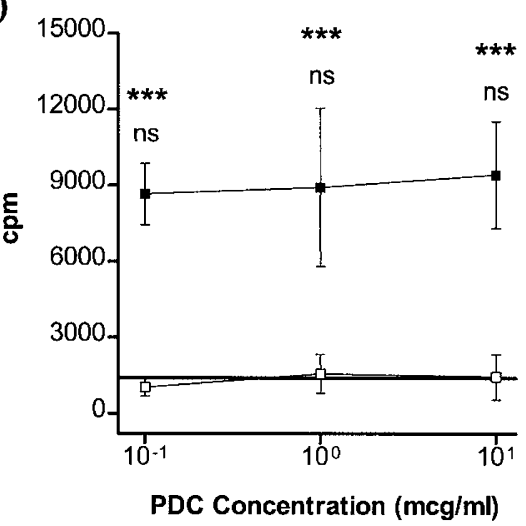

b)

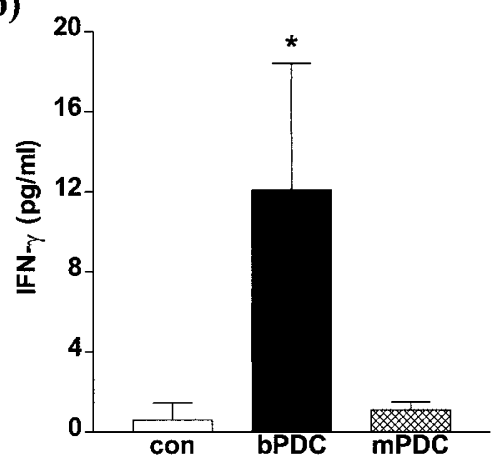

Figure 3.

T-cell proliferative (a) and IFN- $\gamma$ secretory (b) responses of mice sensitized with foreign PDC to foreign PDC (solid squares) and self-PDC (open squares) at a range of protein concentrations. The horizontal line indicates mean control proliferation; each point represents the mean of data from eight animals, and the error bar shows the standard deviation. ${ }^{* * *} p<0.005$ versus control, ${ }^{*} p<0.05$ versus control. ns $=$ not significant.

observed after 8 weeks in animals challenged with CFA alone (data not shown) or with foreign PDC and CFA (Jones et al, 2000).

Liver sections from normal SJL/J mice showed a small number of $\mathrm{CD}^{+}$-positive and $\mathrm{CD} 4^{+}$-positive cells within some portal tracts; almost no $\mathrm{CD}^{+}$cells were observed. The portal tracts in sections from animals sensitized with self-PDC in CFA showed variable but generally mild infiltration with $\mathrm{CD}^{+}$(Fig. $5 \mathrm{~b}$ ) and $\mathrm{CD}^{+}$cells (Fig. $5 \mathrm{c}$ ); again very few $\mathrm{CD} 8^{+}$cells were evident (Fig. 5d). Liver sections from animals cosensitized with foreign and self-PDC showed a further increase in infiltration by $\mathrm{CD}^{+}$and $\mathrm{CD} 4^{+}$cells (Fig. 5, e and f). However, in these sections there was also a marked increased in the proportion of $\mathrm{CD}^{+}$ cells within many of the portal tracts (Fig. $5 \mathrm{~g}$ ).

\section{Morphometric Analysis of the Phenotyped Infiltrate within Portal Tracts of Sensitized and Cosensitized Animals}

Morphometric cell count analysis showed significantly higher levels of $\mathrm{CD}^{+}, \mathrm{CD}^{+}$, and $\mathrm{CD}^{+}$cells infiltrat- ing into portal tracts in self-PDC and foreign-PDC cosensitized animals than in self-PDC only-sensitized animals (CD3, $p<0.01$; CD4, $p<0.005$; CD8, $p<$ 0.005; Fig. 6).

\section{Antigen Specificity of Liver Infiltrating T Cells in Cosensitized Animals}

Significantly greater numbers of liver-infiltrating mononuclear cells could be recovered from self-PDC and foreign PDC cosensitized animals $\left(n=7 ; 6.5 \times 10^{6}\right)$ than from control (self-PDC and CFA only) ( $n=4 ; 2.7$ $\left.\times 10^{6} ; p<0.01\right)$ and unsensitized animals $(n=3,2.9$ $\times 10^{6} ; p<0.01$ ). FACS analysis of whole liverinfiltrating mononuclear cell populations showed that the proportions of $\mathrm{CD} 4^{+}$and $\mathrm{CD} 8^{+} \mathrm{CD}^{+}{ }^{+} \mathrm{T}$ cells were similar in cosensitized and control animals $\left(\mathrm{CD}^{+}\right.$: $61 \% \pm 3 \%$ versus $66 \% \pm 8 \%$; $\mathrm{CD}^{+}: 35 \% \pm 8 \%$ versus $35 \% \pm 3 \%$ ), although given the significant differences in overall mononuclear cell infiltrate numbers between cosensitized and control animals, both total $\mathrm{CD}^{+}$and total $\mathrm{CD}^{+}$liver-infiltrating cell num- 
a)

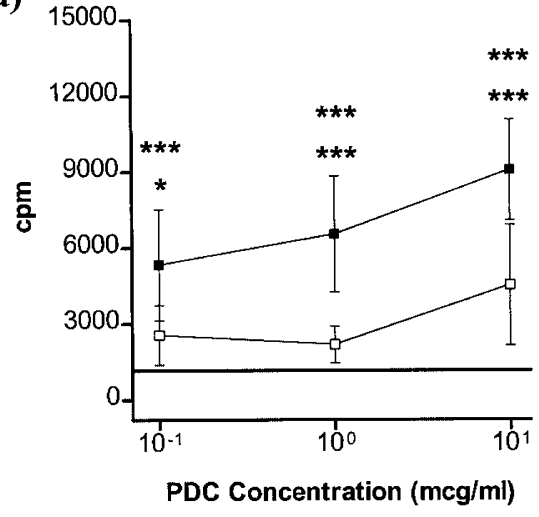

b)

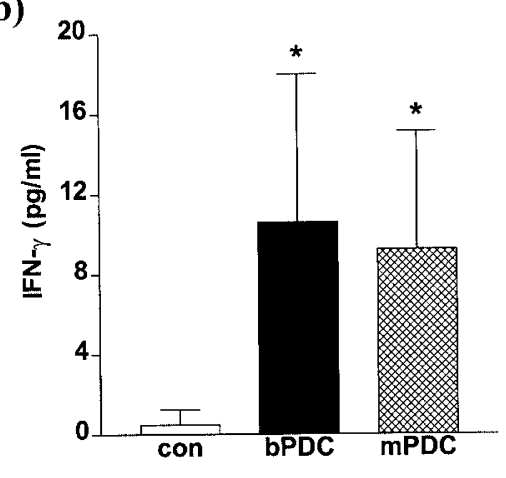

Figure 4.

T-cell proliferative (a) and IFN- $\gamma$ secretory (b) responses of mice cosensitized with self-PDC and foreign PDC to foreign PDC (solid squares) and self-PDC (open squares) at a range of protein concentrations. The horizontal line indicates mean control proliferation; each point represents the mean of data from eight animals, and the error bar shows the standard deviation. ${ }^{\star \star *} p<0.005$ versus control, ${ }^{\star} p<0.05$ verus control. ns $=$ not significant.

bers were significantly increased in the cosensitized animals. The proportion of T cells that were $\mathrm{CD}^{+}$was significantly higher in the liver-infiltrating than in the splenic mononuclear cell populations in the cosensitized animals $(35 \% \pm 8 \%$ versus $23 \% \pm 1 \% ; p<$ 0.05).

The liver-infiltrating T-cell population in the self-PDC and foreign-PDC cosensitized animals contains antiself-PDC-reactive cells as shown by the positive proliferative response to murine PDC in primary culture (Fig. 7a). Autoreactive and bovine PDC specific responses were absent from liver-infiltrating T-cell populations derived from control animals (Fig. 7b).

\section{Discussion}

In this study we have demonstrated that normal SJL/J mice are functionally tolerant of self-PDC, because challenge with purified self-PDC in CFA failed to induce specific B- or T-cell responses that could be detected in vitro. This state of tolerance to self-PDC is similar to that observed in normal human populations (Jones et al, 1997; Palmer et al, 1993) and is consistent with maintenance by either peripheral or central mechanisms (Abbas et al, 1996; Goldrath and Bevan, 1999; Jones and Diamond, 1995). However, appropriate stimulation of SJL/J mice could break T-cell selftolerance. This observation demonstrates the presence of $B$ and $T$ cells with a potential for reactivity with self-PDC in normal SJL/J mice. Examination of the mechanisms responsible for, and the consequences of, breakdown of tolerance in this system may be of importance for our understanding of PBC, a disease characterized by the presence of both $\mathrm{B}$ - and T-cell reactivity to self-PDC (Jones et al, 1997; Palmer et al, 1993).

The present study has confirmed the previous observation that sensitization of SJL/J mice with nonself-PDC induces a significant, isotype-switched, antibody response that is cross-reactive with self-PDC (Jones et al, 1999). This occurs despite the significant degree of sequence identity seen between PDC com- ponents from different mammalian species. Sequence comparison between PDC of human and rat origin (data are not yet available for murine and bovine PDC) show 90\% identity for PDC-E2 (Russell and Guest, 1991) and $99 \%$ and $97 \%$ for the available sequences of the $\mathrm{E} 1 \alpha$ and $\mathrm{E} 1 \beta$ components (Matuda et al, 1992). In contrast to the fully cross-reactive B-cell responses, over the time course of the current study (8 weeks), the splenic T-cell response induced by sensitization with bovine PDC was restricted to epitopes specific for the non-self-bovine protein, because no proliferative or cytokine response was observed after in vitro stimulation with self-PDC. These findings are consistent with the view that B-cell tolerance to self-PDC is normally maintained at the T-cell level but can be broken after activation of $\mathrm{CD}^{+}$helper T cells specific only for non-murine epitopes on the bovine protein, and are in agreement with our previous observations (Jones et al, 1999). This is consistent with the demonstration that antibodies cross-reactive with self-PDC can be produced in the absence of self-PDC reactive $T$ cells after exposure to bacterial PDC (Butler et al, 1995; Klein et al, 1993).

Sensitization of SJL/J mice with a combination of self- and non-self-PDC resulted in a rapid breakdown of tolerance to the self-protein, as shown by the significant lymphoproliferation and IFN- $\gamma$ production observed after in vitro stimulation of splenic mononuclear cells with self-PDC. It is significant that the animals sensitized in this way developed, within 8 weeks of sensitization, characteristic portal tract inflammatory lesions (Jones et al, 2000). The number of $T$ cells infiltrating into the portal tracts and liver parenchyma was significantly elevated in the self-PDC and foreign-PDC cosensitized animals when compared with either unsensitized or control sensitized animals, which showed no breakdown of T-cell self-tolerance. The similarity between the kinetics of the development of T-cell tolerance breakdown and of portal tract inflammation and bile duct lesion formation would seem to implicate $T$ cell-mediated pathways in the 

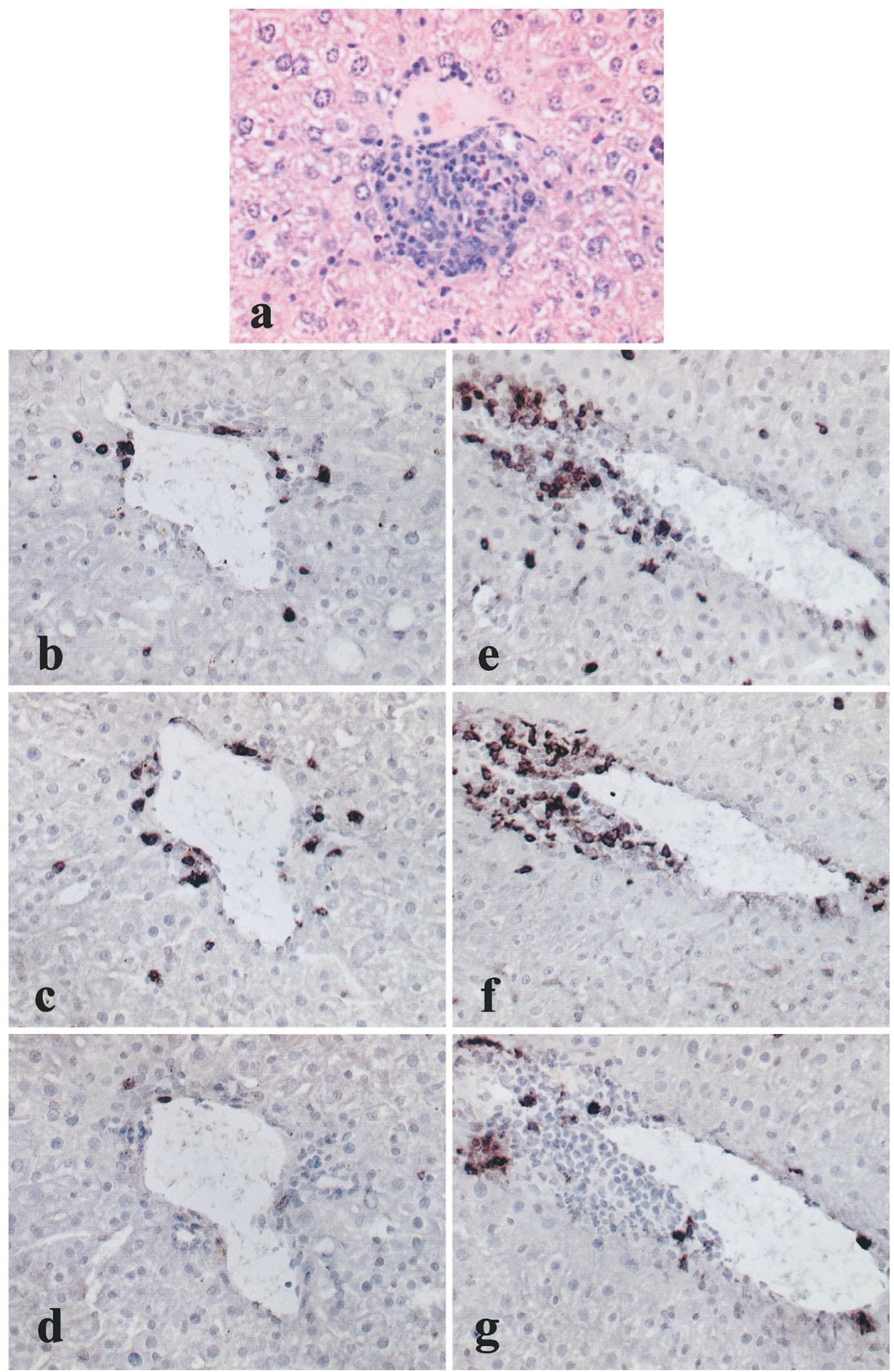

Figure 5.

Liver tissue from a representative mouse cosensitized with self-PDC and foreign PDC stained with hematoxylin and eosin (HE) (a). Liver tissue from representative mice sensitized with self-PDC alone $(b$ to $d$ ) and self-PDC and foreign PDC together ( $e$ to $g$ ) stained with anti-CD3 $(b$ and $e$ ), anti-CD4 ( $c$ and $f)$, and anti-CD8 $(d$ and $g$ ). 


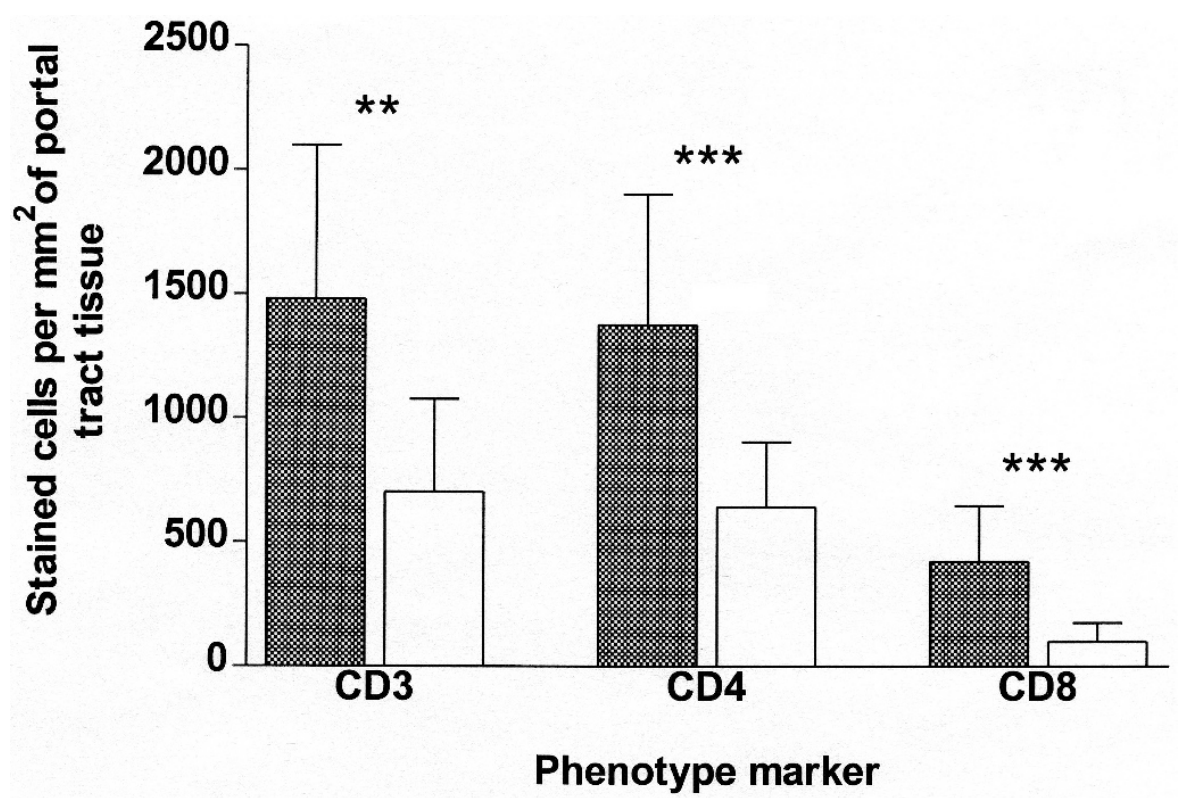

Figure 6.

Quantitative morphometry of $\mathrm{CD}^{+}, \mathrm{CD}^{+}$, and $\mathrm{CD} 8^{+} \mathrm{T}$ cells within the portal tracts of mice sensitized with mixed self-PDC and foreign PDC (hatched column) or with self-PDC alone (open column). The data show the mean result from eight animals in each group; the error bars show the standard deviation of the mean. ${ }^{\star \star *}$ $p<0.005$ versus murine PDC only sensitized mice, ${ }^{\star *} p<0.01$ versus murine PDC sensitized mice.

a)

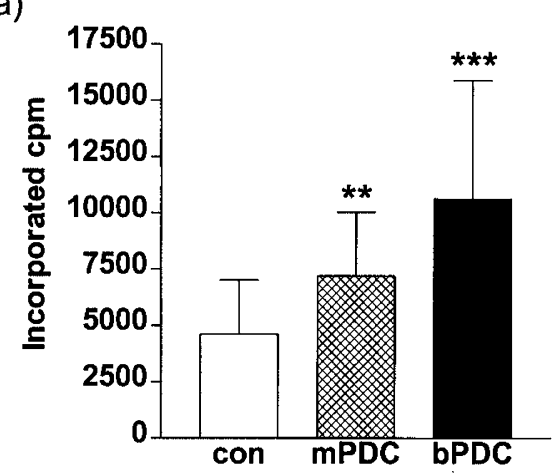

b)

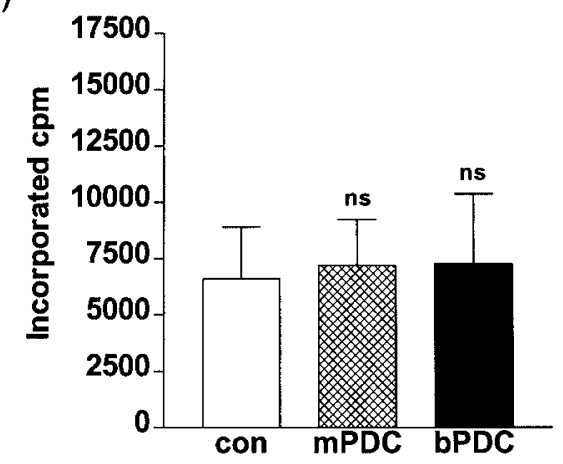

Figure 7.

Proliferative responses of liver-infiltrating T cells derived from (a) self-PDC and foreign PDC cosensitized $(n=7)$ and (b) control mice to mouse PDC (mPDC) and bovine PDC (bPDC). Standard deviation. ${ }^{* *} p<0.005$ versus control, ${ }^{* *} p<0.01$ versus control; ns $=$ not significant.

pathogenesis of the histologic changes. The observation that anti-self-PDC-reactive T cells are present in the liver-infiltrating mononuclear cell population in self-PDC and foreign-PDC cosensitized, but not control sensitized, animals supports the view that autoreactive PDC-specific $\mathrm{T}$ cells are implicated in this process. However, $\mathrm{T}$ cell-adoptive transfer experiments will be necessary to confirm this role.

It is likely that the enhanced kinetics for expansion of PDC-specific autoreactive T cells in animals sensitized with combined non-self-PDC and self-PDC is a consequence of T-cell "epitope spreading" in the presence of both self-PDC and non-self-PDC and activated, cross-reactive $B$ cells. A similar model has been proposed to explain the breakdown of tolerance to self-cytochrome $c$ in animals sensitized with a mixture of self- and foreign-cytochrome $\mathrm{c}$; in this work, adoptive transfer was used to show that B cells play a central role in the process (Mamula et al, 1992). It is possible that cross-reactive B cells take up self-antigen after it has been bound by cell-surface immunoglobulin and then process and efficiently present self-epitopes to potentially autoreactive $\mathrm{T}$ cells (Mamula and Janeway, 1993). Indeed, a recent study has confirmed that activated $B$ cells can prime naïve $T$ cells and break immune tolerance (Constant, 1999). Alternatively, cross-reactive antibodies could bind the self-antigen and form immune complexes, which are taken up and processed and the selfepitopes presented efficiently by dendritic cells (Fuchs and Matzinger, 1993). Whatever the mechanism, the capacity for $\mathrm{T}$-cell responses to foreign PDC to spread to self-PDC, and the apparent association between this process and the development of liver pathology, has clear implications for the pathogenesis of PBC, given the potential for immunologic coexposure to 
self-PDC and foreign PDC to occur during bacterial infection.

\section{Materials and Methods}

\section{Antigens}

Bovine PDC (foreign PDC) was purified from heart muscle using the method described by Stanley and Perham (1980). Purity of the PDC preparation was assessed by SDS-PAGE. Mouse PDC (self-PDC) was purified from heart tissue using a scaled-down protocol, but the final differential polyethylene glycol step, separating PDC from the related 2-oxoglutarate dehydrogenase complex, was omitted in the purification of self-PDC. All protein concentrations used for sensitization were based on the concentration of PDC alone. Protein preparations were stored at $-20^{\circ} \mathrm{C}$ before use.

\section{Immunization}

Female SJL mice were obtained from Harlan Olac (Bicester, Oxfordshire, United Kingdom). Sensitization was performed at 12 to 16 weeks of age when the mice were injected intraperitoneally in groups with one of the following: (a) foreign PDC (500 $\mu \mathrm{g}$ in $100 \mu \mathrm{l}$ of saline) emulsified 1:1 (v/v) with CFA (consisting of Mycobacterium tuberculosis strain H37Ra (Difco, Detroit, Michigan; $10 \mathrm{mg} / \mathrm{ml}$ ) in incomplete Freund's adjuvant as previously described (Jones et al, 1999, 2000); (b) self-PDC emulsified with CFA as above; or (c) a mixture of self-PDC and foreign PDC emulsified with CFA as above.

All mice were subjected to a single sensitization and were killed after 8 weeks. This study was performed to appropriate ethical standards under UK Home Office License. Quantities of protein used for sensitization were consistent with license constraints.

\section{Anti-PDC Antibody Characterization}

Blood was obtained by terminal bleed and serum prepared by centrifugation of clotted blood. Samples were stored at $-20^{\circ} \mathrm{C}$. The specificity of serum antibody was studied by immunoblotting. Briefly, foreign PDC or self-PDC was resolved by SDS-PAGE on 10\% gels and transferred electrophoretically to Fluorotrans (polyvinylidene difluoride) transfer membrane (Pall Europe Ltd., Portsmouth, United Kingdom). Polyvinylidene difluoride strips were blocked with $5 \%(\mathrm{w} / \mathrm{w})$ skimmed milk powder and incubated with diluted $(1: 1000)$ sera for 2 hours. Bound antibodies were detected using secondary goat anti-mouse IgG peroxidase-conjugated antibody (Sigma Chemical, Poole, Dorset, United Kingdom). The peroxidase reaction was visualized using the Vector VIP substrate kit (Vector Laboratories, Burlingame, California).

\section{Mononuclear Cell Preparation}

Tissue was derived, in all cases, from mice at 8 weeks after sensitization.
Spleen Mononuclear Cells. Spleens were removed intact and washed in RPMI 1640 (Sigma; the capsule was teased away using forceps. The tissue was disaggregated by passage through a $100-\mu \mathrm{m}$ metal mesh, and splenic mononuclear cells were purified by density gradient centrifugation on Histopaque 1.083 (Sigma) at $400 \times g$ for 30 minutes. The interfacial cells were recovered, washed three times in complete medium (RPMI 1640, 5\% FCS, and penicillin/streptomycin [100 U/ml, $0.1 \mathrm{mg} / \mathrm{ml}$ ] [all Sigma]), and counted.

Liver-Infiltrating Mononuclear Cells. Liver-infiltrating mononuclear cells were isolated using a modification of previously described methods (Dao et al, 1998). Briefly, the liver was perfused in situ through the portal vein with $5 \mathrm{ml}$ of RPMl medium containing $0.2 \mathrm{mg} / \mathrm{ml}$ collagenase, $0.02 \mathrm{mg} / \mathrm{ml}$ DNase, and 5\% FCS (digestion buffer) (all reagents from Sigma). After perfusion livers were homogenized using a metal mesh and further digested with $10 \mathrm{ml}$ of digestion buffer. The majority of hepatocytes were removed by centrifugation at $30 \times g$ for 3 minutes. The supernatant was then centrifuged at $650 \times g$ for 10 minutes to obtain a pellet of nonparenchymal cells. Mononuclear cells were then prepared by density gradient centrifugation on Histopaque 1.083 (Sigma) at $400 \times g$ for 30 minutes and counted. The use of a protocol with an in situ liver perfusion stage ensures that mononuclear cell recovery is restricted to cells infiltrating the liver tissue rather than peripheral blood mononuclear cells undergoing hepatic vascular transit.

\section{Proliferation Assays}

The proliferation of antigen-specific splenic and liverinfiltrating $\mathrm{T}$ lymphocytes was assayed by measurement of $\left[{ }^{3} \mathrm{H}\right]$ thymidine incorporation into DNA. Splenic or liver mononuclear cells $\left(2 \times 10^{5}\right)$ were aliquoted per well, in a final volume of $200 \mu \mathrm{l}$ of complete medium in 96-well U-bottomed plates (Costar, Cambridge, Massachusetts). Filter-sterilized bovine PDC or murine PDC was added at a range of final concentrations. Pentuplicate repeats were used for each antigen concentration and for control wells that contained no antigen. After 96 hours in culture at $37^{\circ} \mathrm{C}$ under $5 \%$ $\mathrm{CO}_{2}, 100 \mu \mathrm{l}$ of culture medium was removed from each well and stored at $-70^{\circ} \mathrm{C}$ before cytokine assay by ELISA. Each well in the culture plate was then pulsed with $1 \mu \mathrm{Ci}$ of $\left[{ }^{3} \mathrm{H}\right]$ thymidine (Amersham International, Buckinghamshire, United Kingdom; $2.0 \mathrm{Ci} /$ $\mathrm{mmol}$ ) in $30 \mu \mathrm{l}$ of complete medium. After a further 18 hours in culture, the cells were harvested and the DNA incorporated radiation was assayed by liquid scintillation counting.

\section{IFN- $\gamma$ Assay}

Cytokine measurement was performed on culture supernatants aspirated from each lymphocyte assay well as described previously (Jones et al, 1999). Supernatants were specifically assayed for IFN- $\gamma$ by standard sandwich ELISA. Briefly, capture antibody (clone R46A2; Cambridge Bioscience, Cambridge, United King- 
dom) was coated $(2.5 \mu \mathrm{g} / \mathrm{ml})$ overnight at $4^{\circ} \mathrm{C}$ onto ELISA plates (Immulon 4; Dynex Technologies, United Kingdom) in carbonate binding buffer ( $\mathrm{pH}$ 9.6). Supernatant samples and IFN- $\gamma$ standards ( 1 to $1000 \mathrm{pg} / \mathrm{ml}$ ) were incubated overnight at $4^{\circ} \mathrm{C}$ with shaking. After washing, bound antigen was detected using a biotinylated detection antibody $(0.5 \mu \mathrm{g} / \mathrm{ml}$, clone XMG1.2; Cambridge Bioscience) followed by incubation with Immunopure streptavidin horseradish peroxidase conjugate (1 $\mu \mathrm{g} / \mathrm{ml}$; Pierce, Rockford, Illinois). Peroxidase reactivity was visualized using the substrate o-phenylenediamine in the presence of $\mathrm{H}_{2} \mathrm{O}_{2}$. The reaction was terminated with $2 \mathrm{M} \mathrm{H}_{2} \mathrm{SO}_{4}$ and absorbance was measured at $492 \mathrm{~nm}$. IFN- $\gamma$ concentrations are expressed in $\mathrm{pg} / \mathrm{ml}$.

\section{Phenotypic Analysis}

Splenic and liver-infiltrating mononuclear cell populations were characterized phenotypically by immunofluorescence labeling and flow cytometry using a FACScan flow cytometer (Becton Dickinson Immunocytometry Systems, Oxford, United Kingdom) and the lysis II software package (Becton Dickinson). Cells were stained with optimal concentrations of anti-CD3 PerCP (clone 145-2C11), anti-CD4 FITC (RM4-5), and anti-CD8 FITC (53-6.7) (all PharMingen, San Diego, California). Cells $\left(10^{4}\right)$ were counted per sample. Flow cytometer acquisition characteristics were set up after following the manufacturer's recommendations.

\section{Liver Histology and Immunohistochemistry}

Liver tissue (10-mm pieces) was taken from each animal for snap-freezing in isopentane in liquid nitrogen and fixation in formalin. Paraffin-embedded fixed tissue sections were cut at $5 \mu \mathrm{M}$ and stained with $\mathrm{HE}$.

Serial cryostat sections were stained with antibodies to detect CD3-positive (Serotec, Oxford, United Kingdom), CD4-positive (PharMingen), and CD8positive (PharMingen) cells using a standard streptavidin biotin indirect immunoperoxidase technique. Isotype negative controls (Serotec) were performed in parallel. Briefly, after acetone fixation, sections were rehydrated and endogenous peroxidase activity was minimized by incubation for 10 minutes in $0.2 \mathrm{M}$ sodium azide in PBS with $0.3 \%$ hydrogen peroxide. Endogenous biotin was subsequently blocked using a "biotin-blocking" kit obtained from Dako Ltd. (Buck, United Kingdom) and nonspecific binding of immune reagents was minimized by incubation with $20 \%$ normal rabbit serum (Gibco BRL, United Kingdom) in tris-buffered saline. Incubation with primary antibodies at optimum dilutions was at $4^{\circ} \mathrm{C}$ overnight, and bound antibody was detected with biotinylated rabbit anti-mouse immunoglobulin [F(ab')2 fragments; Serotec], preincubated with mouse serum. Binding was visualized using streptavidin biotin peroxidase complex (Dako) with hydrogen peroxidase/nickelenhanced diaminobenzidine as substrate/chromagen.

\section{Tissue Section Analysis}

HE-stained liver sections were used for morphologic assessment of necroinflammation and bile duct injury. In addition, CD3-, CD4-, and CD8-positive cells were separately enumerated in 5 portal tracts, randomly selected, in immunohistochemically stained liver sections from 8 murine PDC sensitized and 8 murine PDC/bovine PDC cosensitized animals. Morphometric image analysis was performed using a Kontron Image analyser running Vidas 2.1 software and $a \times 10$ objective lens. An interactive cell-counting method was devised using a custom-designed "macro." Briefly, the selected region around a portal tract and the lumen of the associated portal vein were delineated "on screen." Thus, the area occupied by the lumen of the portal vein was excluded from the analysis. Cell counts were performed at $\times 40$ magnification. Both the area analyzed and the total cells counted, in that area, were stored in a database. Results were expressed as numbers of labeled cells per square millimeter of portal tract cross section for each liver section.

\section{Statistical Analysis}

Differences between experimental groups for all parameters were compared by parametric $t$ test (Student).

\section{References}

Abbas AK, Murphy KM, and Sher A (1996). Functional diversity of helper T lymphocytes. Nature 383:787-793.

Burroughs AK, Rosenstein IJ, Epstein O, Hamilton-Miller JM, Brumfitt W, and Sherlock S (1984). Bacteriuria and primary biliary cirrhosis. Gut 25:133-137.

Butler P, Hamilton-Miller J, Baum $\mathrm{H}$, and Burroughs AK (1995). Detection of M2 antibodies in patients with recurrent urinary tract infection using an ELISA and purified PBC specific antigens: Evidence for a molecular mimicry mechanism in the pathogenesis of primary biliary cirrhosis. Biochem Mol Biol Int 35:473-485.

Butler P, Valle F, Hamilton-Miller JM, Brumfitt W, Baum H, and Burroughs AK (1993). M2 mitochondrial antibodies and urinary rough mutant bacteria in patients with primary biliary cirrhosis and in patients with recurrent bacteriuria. J Hepatol $17: 408-414$

Constant SL (1999). B lymphocytes as antigen-presenting cells for $\mathrm{CD}^{+}{ }^{+}$T-cell priming in vivo. J Immunol 162:56965703.

Dao T, Mehal WZ, and Crispe N (1998). IL-18 augments perforin-dependent cytotoxicity of liver NK-T cells. J Immunol 161:2217-2222.

Dubel L, Tanaka A, Leung PS, Van de Water J, Coppel R, Roche T, Johanet C, Motokawa Y, Ansari A, and Gershwin ME (1999). Autoepitope mapping and reactivity of autoantibodies to the dihydrolipoamide dehydrogenase-binding protein (E3BP) and the glycine cleavage proteins in primary biliary cirrhosis. Hepatology 29:1013-1018.

Floreani A, Bassendine MF, Mitchison H, Freeman R, and James OFW (1989). No specific association between primary biliary cirrhosis and bacteriuria. J Hepatol 8:201-207. 
Fuchs $E$ and Matzinger $P$ (1993). B cells drive diversification but not directly. Immunol Today 14:153.

Goldrath AW and Bevan MJ (1999). Selecting and maintaining a diverse T-cell repertoire. Nature 402:255-262.

Haydon GH and Neuberger JM (2000). PBC: An infectious disease? Gut 47:586-588.

Howel D, Fischbacher CM, Bhopal RS, Gray J, Metcalf JV, and James OFW (2000). An exploratory population-based case-control study of primary biliary cirrhosis. Hepatology 31:1055-1060

Jones DEJ and Diamond AG (1995). The basis of autoimmunity: An overview. Ball Clin Endocrinol Metabol 9:1-24.

Jones DEJ, Palmer JM, Kirby JA, De Cruz DJ, McCaughan GW, Sedgewick JD, Yeaman JD, Burt AD, and Bassesndine MF (2000). Experimental autoimmune cholangitis: A mouse model of immune-mediated cholangiopathy. Liver 20:351356.

Jones DEJ, Palmer JM, Yeaman SJ, Bassendine MF, and Diamond AG (1997). T-cell responses to natural human proteins in primary biliary cirrhosis. Clin Exp Immunol 116: 562-568.

Jones DEJ, Palmer JM, Yeaman SJ, Kirby JA, and Bassendine MF (1999). Breakdown of tolerance to pyruvate dehydrogenase complex in experimental autoimmune cholangitis: A murine model of primary biliary cirrhosis. Hepatology 30:65-70.

Klein R, Wiebel M, Engelhart S, and Berg PA (1993). Sera from patients with tuberculosis recognize the M2a-epitope (E2-subunit of pyruvate dehydrogenase complex) specific for primary biliary cirrhosis. Clin Exp Immunol 92:308-316.

Krams SM, Surh CD, Coppel RL, Ansari AA, Reubner B, and Gershwin ME (1989). Immunization of experimental animals with dihydrolipoamide acetyltransferase, as a purified recombinant polypeptide, generates mitochondrial antibodies but not primary biliary cirrhosis. Hepatology 9:411-416.

Mamula MJ and Janeway CA (1993). Do B cells drive the diversification of immune responses? Immunol Today 14: 151-152.

Mamula MJ, Lin RH, Jameway CA, and Hardin JA (1992). Breaking $T$ cell tolerance with foreign and self coimmunogens: A study of B and T cell epitopes of cytochrome c. J Immunol 149:789-795.
Matuda S, Nakano K, Ohta S, Shimura M, Yamanaka T, Nakagawa S, Titani K, and Miyata T (1992). Molecular cloning of dihydrolipoamide acetyltransferase of the rat pyruvate dehydrogenase complex: Sequence comparison and evolutionary relationship to the other dihydrolipoamide acetyltransferases. Biochem Biophys Acta 1131:114-118.

Mayo I, Arizti P, Pares A, Oliva J, Doforno RA, Rosa de Sagarra M, Rodes J, and Castano JG (2000). Antibodies against the $\mathrm{COOH}$-terminal region of $E$. coli ClpP protease in patients with primary biliary cirrhosis. J Hepatol 33:528-536.

Palmer JM, Bassendine MF, James OFW, and Yeaman SJ (1993). Human pyruvate dehydrogenase complex as an autoantigen in primary biliary cirrhosis. Clin Sci 85:289-293.

Palmer JM, Jones DEJ, Quinn J, McHugh A, and Yeaman SJ (1999). Characterization of the autoantibody responses to recombinant $\mathrm{E} 3$ binding protein (protein $\mathrm{X}$ ) of pyruvate dehydrogenase in primary biliary cirrhosis. Hepatology 30:21-26.

Russell GC and Guest JR (1991). Sequence similarities within the family of dihydrolipoamide acyltransferases and discovery of a previously unidentified fungal enzyme. Biochim Biophys Acta 1076:225-232.

Shimoda S, Nakamura M, Ishibashi $\mathrm{H}$, Hayashida K, and Niho Y (1995). HLA DRB4 0101-resticted immunodominant T-cell autoepitope of pyruvate dehydrogenase complex in primary biliary cirrhosis: Evidence of molecular mimicry in human autoimmune disease. J Exp Med 181:1835-1845.

Stanley CJ and Perham RN (1980). Purification of the 2-oxo acid dehydrogenase complexes from ox heart by a new method. Biochem J 191:147-154.

Surh CD, Coppel R, and Gerswin ME (1990). Structural requirement for autoreactivity on human pyruvate dehydrogenase-E2, the major autoantigen of primary biliary cirrhosis. J Immunol 144:3367-3374.

Yeaman SJ, Kirby JA, and Jones DEJ (2000). Autoreactive responses to pyruvate dehydrogenase complex in the pathogenesis of primary biliary cirrhosis. Immunol Rev 174:238249 . 